\title{
Alexithymic characteristics in pediatric patients with primary headache: a comparison between migraine and tension-type headache
}

\author{
M. Gatta ${ }^{1}$, C. Spitaleri ${ }^{2}$, U. Balottin ${ }^{3,4}$, A. Spoto ${ }^{5}$, L. Balottin ${ }^{6 *}$, S. Mangano ${ }^{2}$ and P.A. Battistella
}

\begin{abstract}
Background: Alexithymia is a personality construct characterized by difficulties in verbal emotional expression and a limited ability to use one's imagination. Evidence of alexithymic characteristics was found in adults suffering from headache, while little is known about children. The aim of this study was to establish the prevalence of alexithymia in two different subgroups of children and adolescents suffering from primary headache. We also looked for correlation between alexithymia in children and in their mothers.
\end{abstract}

Methods: This study involved 89 participants: 47 (11 males, 36 females, aged 8 to 17 years) suffering from tensiontype headache (TTH), and 42 (18 males, 24 females, aged 8 to 17 years) suffering from migraine $(\mathrm{M})$, based on the International Classification of Headache Disorders (ICHD 2013). A control group of 32 headache-free subjects (26 females and 6 males, aged 8 to 17 years) was also considered. Two questionnaires were administered to measure alexithymia: the Alexithymia Questionnaire for Children to young patients and controls, and the Toronto Alexithymia Scale (TAS-20) to the mothers.

Results: Higher rates of alexithymia emerged in the TTH group compared to the M group. In particular, TTH sufferers had difficulty identifying their feelings. The mothers of children with headaches didn't score higher in alexithymia compared to other mothers. In the $\mathrm{M}$ and in the control group, there was a significant correlation between the rates of alexithymia in young people and in their mothers.

Conclusions: To date no other study has investigated alexithymia in subgroups of primary headaches in developmental age. Our results suggest that patients suffering from $\mathrm{TH}$ are more alexithymic than $\mathrm{M}$ patients. This pave the way to etiopathogenetic and clinical considerations, calling for a comprehensive and multidisciplinary approach to tackle the problem of headache.

Keywords: Alexithymia; Toronto Alexithymia Scale; Alexithymia Questionnaire for Children; Tension-type headache; Migraine

\section{Background}

The term alexithymia, which literally means "no words for feelings", refers to a cognitive-affective impairment characterized by a limited capacity to experience and express emotions [1-4]. The most important features of alexithymia are: (a) a difficulty identifying feelings and distinguishing between feelings and the bodily sensations of emotional arousal; (b) difficulty describing feelings to

\footnotetext{
* Correspondence: laura.balottin@libero.it

${ }^{6}$ Department of Philosophy, Sociology, Education, and Applied Psychology, Section of Applied Psychology, University of Padova, Padova, Italy
} Full list of author information is available at the end of the article others; (c) constricted imaginative processes; and (d) a stimulus-bound, externally oriented cognitive style [4]. Several theories of the etiology of alexithymia have been proposed. Some suggest that childhood events such as traumatic experiences and/or a dysfunctional parentchild relationship can contribute to alexithymia [5] while other works suggest relating nonverbal emotion recognition in alexithymia with a dysfunction of the right hemisphere $[3,6,7]$. Alexithymia can be linked to a deficiency in inter-hemispheric transfer of information from the right to the left hemisphere [8, 9], referred to by Hoppe as a "functional commissurotomy" [8].

\section{实 Springer}


Another theory attributes the pathogenesis of alexithymia to depleted dopamine levels in the anterior cingulate cortex or the orbitofrontal cortex [3, 10].

Several mechanisms may explain the way genetic factors contribute to individual differences in alexithymia: the genes potentially involved in the variability of alexithymic traits may influence the transcription of neuroreceptors or neurotransmitters, or may affect neural development [11]. Some family studies found a significant relation between mothers' and fathers' alexithymia scores and those of their children's [12], suggesting a possible intergenerational transmission of alexithymia. However they cannot determine whether the clustering in the families observed is correlated to genetics or environmental influences. The design of a twin study is the most suited to disentangle the role of nature versus nurture, but to date there are few twin studies on alexithymia [12-15]. Two pioneering studies suggested important genetic influences in alexithymia $[12,13]$. Nevertheless more recent studies have shown that genetic factors accounted for one third of the variance in TAS-20 scores, while unshared environmental factors accounted for most of the variation in alexithymia $[14,15]$.

The aim of this study is to investigate alexithymic characteristics of children and adolescents with primary headache and their mothers to verify whether there is a possible relationship between headache and emotional regulation, in particular alexithymia. A wide range of psychiatric disorders, in fact, seemed to be linked to primary headache and preexisting mental disorders are likely to increase the risk for the onset of headache [16]. Moreover, headaches are more common in families with a history of psychological disorders: mood and anxiety disorders run in families, just like headache symptoms, and they were shown to be more common in the parents of children with headache [17]. This points to the importance of assessing a broad range of psychiatric conditions and psychological traits, it includes alexithymia, in children and their parents, to discover important stressors and risk factors for the onset of headaches in genetically predisposed children [16-18].

There are few studies on the relationship between headache and alexithymia in adults, and still fewer on the issue related to children and adolescents [19]. Wise et al. [20] compared adult patients with migraine (M) or tension-type headache (TTH) with healthy controls, finding higher alexithymia scores in headache sufferers, irrespective of whether they had M or TTH. Yücel et al. [21] demonstrated higher levels of alexithymia in patients aged 18-65 suffering from episodic or chronic TTH than in healthy controls, once again with no difference in the severity of alexithymia between the cases experiencing episodic versus chronic TTH.
By means of a case-control study, we investigated a sample of pediatric patients suffering from primary headache ( $\mathrm{M}$ or TTH), to detect any alexithymic characteristic. Assuming that the construct might depend on the relationship with the primary caregiver, the alexithymic dimension was also investigated in the patients' mothers, comparing the levels of alexithymia obtained by the mothers with those of their children.

We therefore had three objectives:

- to establish whether a statistically significant difference in alexithymic traits exists among $M$ patients, TTH patients and controls;

- to seek any statistically significant correlation between the alexithymic scores obtained by the children/adolescents and those obtained by their mothers;

- to identify any statistically significant association between age, gender and alexithymic score.

\section{Methods}

\section{Participants}

The study involved 47 TTH sufferers (11 males and 36 females) aged 8 to 17 years (mean $12.4 \pm 2.3$ ) and $42 \mathrm{M}$ sufferers (18 males and 24 females) aged 8 to 17 years old (mean 13.1 $\pm 2,4$ ), attending the Center for the Diagnosis and Treatment of Juvenile Headache at the Universities of Padova and Pavia. The inclusion criteria were TTH and $\mathrm{M}$, diagnosed at least 6 months previously, with no pharmacological prophylaxis. The diagnosis was based on the ICHD (The International Classification of Headache Disorders $3^{\text {rd }}$ edition/beta version 2013) [22]. Within the TTH group, 20 (43\%) out of the 47 participants were diagnosed with chronic $\mathrm{TTH}$, while $8(17 \%)$ and 19 (40 \%) suffered from frequent episodic and infrequent episodic TTH respectively. Concerning the M group, 27 (64\%) out of the 42 patients were diagnosed with $\mathrm{M}$ without aura and 15 (36\%) with $\mathrm{M}$ with aura.

The control group (CG) consisted of 32 subjects ( 6 males and 26 females) aged 8 to 17 years (mean $11.8 \pm 1.6)$ recruited among patients of three medical practitioners in Padova during a routine pediatric check-up at the practitioners' outpatient offices. A semistructured clinical interview was conducted with the mother to collect information on clinical-medical history, including the family's physiological, recent and remote, pathological medical history, focusing particularly on any symptoms of headache. A medical history of headaches or organic diseases and paternal or maternal familiarity for headaches were considered exclusion criteria to be included in the CG. 


\section{Measures}

Children answered an Italian form of the Alexithymia Questionnaire for Children (AQC) [23], a simplified version of the 20-Item Toronto Alexithymia Scale (TAS-20) [24]. The mothers were administered semistructured medical history interviews and had to answer the validated Italian version [25] of the Toronto Alexithymia Scale (TAS-20), the most widely used questionnaire for the assessment of alexithymia in adulthood. The TAS 20 is a 20 -item self-rating questionnaire that measures the following factors: F1, difficulty identifying feelings; F2, difficulty describing feelings; and F3, externally oriented thinking. The results that emerged from the questionnaire were used to classify the subjects into three groups: non-alexithymic, borderline and alexithymic (score $=/>61)$.

\section{Analisys}

The scores obtained on the AQC and on TAS-20 were analysed with ANOVA in order to seek any statistically significant difference in the levels of alexithymia among the groups included in our sample. Bivariate parametric correlations for continuous variables, using Pearson's $r$ coefficient, were run on paired samples to establish the nature of any correlations between the alexithymia levels in the young patients and in their mothers. Bivariate parametric correlations for continuous variables, using Pearson's r coefficient, were also run to explore the relationship between age and alexithymia. Finally, parametric $t$ test was applied to find any potential gender difference in alexithymic scores.

Data were analyzed with SPSS software version 19 (Statistical Package for the Social Sciences).

\section{Results}

Concerning alexithymia scores in children, $38 \%$ of the TTH sufferers, $12 \%$ of the M sufferers, and $9 \%$ of the controls were classified as alexithymic (Table 1).

Considering the children's total score in alexithymia and the subscales separately (F1: difficulty identifying feelings; F2: difficulty describing feelings; F3: externally oriented thinking), significant differences emerged in the

Table 1 Distribution of the children's alexithymia

\begin{tabular}{llll}
\hline & $\begin{array}{l}\text { Alexithymic } \\
\mathrm{n}(\%)\end{array}$ & $\begin{array}{l}\text { Borderline } \\
\mathrm{n}(\%)\end{array}$ & $\begin{array}{l}\text { Non-alexithymic } \\
\mathrm{n}(\%)\end{array}$ \\
\hline $\begin{array}{l}\text { M patients } \\
(n=42)\end{array}$ & $5(12 \%)$ & $10(24 \%)$ & $27(64 \%)$ \\
$\begin{array}{l}\mathrm{T} \text { TH patients } \\
(n=47)\end{array}$ & $18(38 \%)$ & $11(24 \%)$ & $18(38 \%)$ \\
$\begin{array}{l}\text { Controls } \\
(n=32)\end{array}$ & $3(9 \%)$ & $13(41 \%)$ & $16(50 \%)$ \\
\hline
\end{tabular}

Scores based on the Alexithymia Questionnaire for Children obtained by the $\mathrm{M}$, the $\mathrm{TTH}$ and the control groups

$M$ migraine, $T H$ tension-type headache
Table 2 Distribution of the mothers' alexithymia

\begin{tabular}{llll}
\hline & Alexithymic & Borderline & Non-alexithymic \\
\hline $\begin{array}{l}\text { Mothers of M sufferers } \\
(n=39)\end{array}$ & $5(13 \%)$ & $4(10 \%)$ & $30(77 \%)$ \\
$\begin{array}{l}\text { Mothers of TTH sufferers } \\
(n=47)\end{array}$ & $3(6 \%)$ & $4(9 \%)$ & $40(85 \%)$ \\
$\begin{array}{l}\text { Mothers of controls } \\
(n=32)\end{array}$ & $2(6 \%)$ & $9(28 \%)$ & $21(66 \%)$ \\
\hline
\end{tabular}

Scores based on the Toronto Alexithymia Scale (TAS-20) obtained by the mothers of young people in the two clinical groups and the control group $M$ migraine, $T H H$ tension-type headache

total score $(\mathrm{F}=3.19 ; p=.04)$ and in $\mathrm{F} 1(\mathrm{~F}=4.11 ; p=.02)$, with young $\mathrm{TTH}$ patients scoring higher in alexithymia compared to the controls and $\mathrm{M}$ patients of the same age (Table 1).

When comparing the mothers' levels of alexithymia (Table 2), the percentage of mothers classified as alexithymic was $13 \%$ among the mothers of $M$ sufferers, $6 \%$ among the mothers of TTH patients, and 6\% among the mothers of controls: differences were not statistically significant $(\mathrm{F}=2.92 ; p=.06)$.

Our second aim was to find a correlation between alexithymic scores of patients (and controls) and alexithymic scores of their mothers. Differently from their children, the mothers of TTH patients and those of the $\mathrm{M}$ patients did not score higher in alexithymia compared to the mothers of the controls. However children with high scores appear to be associated with mothers with high scores in the $M$ as well as in the control group: significant correlations between alexithymic total scores of $\mathrm{M}$ patients and of their mother and between alexithymic scores of controls and of their mother were found, while the correlation between TTH patients and their mother was not statistically significant (Table 3 ).

In terms of gender, there were no statistically significant relations between this variable and the alexithymia scores in our sample, the only exception being the F3 factor in the $M$ group: males suffering from $M$ in fact scored higher in F3 than females $(\mathrm{t}=2.71 ; p=0.01)$.

Table 3 Mother-child correlations in the alexithymic scores

\begin{tabular}{|c|c|c|c|c|}
\hline & $\begin{array}{l}\text { Total } \\
r(p)\end{array}$ & $\begin{array}{l}\mathrm{F} 1 \\
\mathrm{r}(\mathrm{p})\end{array}$ & $\begin{array}{l}\text { F2 } \\
r(p)\end{array}$ & $\begin{array}{l}\text { F3 } \\
r(p)\end{array}$ \\
\hline $\begin{array}{l}\text { M patients and their } \\
\text { mothers }(n=39)\end{array}$ & $.44^{* *}(<.01)$ & $.39 *(.01)$ & $.36^{*}(.02)$ & $.07(.66)$ \\
\hline $\begin{array}{l}\text { TTH patients and their } \\
\text { mothers }(n=47)\end{array}$ & $.27(.06)$ & $.29(.05)^{*}$ & $.09(.54)$ & $.03(.83)$ \\
\hline $\begin{array}{l}\text { Controls and their } \\
\text { mothers }(N=32)\end{array}$ & $.38^{*}(.03)$ & $.17(.34)$ & $.18(.33)$ & $.24(.19)$ \\
\hline \multicolumn{5}{|c|}{$\begin{array}{l}\text { Alexithymic scores obtained using the Alexithymia Questionnaire for Children } \\
\text { for patients and controls and the Toronto Alexithymia Scale for their mothers, } \\
\text { Total score, F1 difficulty identifying feelings, F2 difficulty describing feelings, } \\
\text { F3 externally oriented thinking } \\
M \text { migraine, TTH tension-type headache } \\
{ }^{*} p<.05{ }^{* *} p<.01\end{array}$} \\
\hline
\end{tabular}


In the TTH group only, there was a statistically significant correlation between age and total alexithymia score, F1 and F3 (Table 4).

\section{Discussion}

Young TTH sufferers scored higher in alexithymia and revealed greater difficulty in identifying feelings (F1) compared to $\mathrm{M}$ sufferers and controls of the same age. Previous studies found headache patients to be more alexithymic than controls [19-21]. Concerning adult samples, Wise et al. [20] in comparing 100 adult patients, $\mathrm{M}$ or TTH sufferers, with a group of healthy controls, found higher alexithymia scores in the former. However in this study [20] no differences emerged between patients with $\mathrm{M}$ and patients with TTH. Yücel et al. [21] demonstrated higher levels of alexithymia in patients aged 18-65 years suffering from episodic or chronic TTH than in healthy controls. No differences in the severity of alexithymia were found in cases experiencing episodic versus chronic TTH. Pini et al. [26], in line with such results found alexithymic characteristics linked to stress symptoms in chronic TTH patients, and to a greater extent in those with medication-overuse headache. There was also preliminary evidence in this sense among preadolescent and adolescent patients with TTH, who scored higher in alexithymic features compared with controls of the same age [19].

Our study confirms a significant relation between TTH and alexithymia but not between M and alexithymia in a child and adolescent sample. A few studies in the adult population have nonetheless revealed a greater extent of alexithymic characteristics in $\mathrm{M}$ patients compared to the general population [27-29]. Children and adolescent samples can however yield different results. A possible explanation for the difference between the alexithymia in TTH and in M patients lies in the different pathogenesis of the two disorders. While in $\mathrm{M}$ genetic factors may be the most important factors, TTH has a complex multifactorial pathogenesis, which also involves various biological, psychological, social and other factors, especially in childhood and adolescence.

Table 4 Correlations between alexithymia and age

\begin{tabular}{lllll}
\hline & Total & $F 1$ & $F 2$ & $F 3$ \\
& $r(p)$ & $r(p)$ & $r(p)$ & $r(p)$ \\
\hline M patients $(n=42)$ & $.12(.43)$ & $.10(.52)$ & $-.01(.93)$ & $.18(.25)$ \\
TTH patients $(n=47)$ & $-.43^{* *}(<.01)$ & $-.36^{*}(.01)$ & $-.22(.14)$ & $-.49^{* *}(<.01)$ \\
Controls $(n=32)$ & $-.09(.63)$ & $.09(.60)$ & $-.15(.42)$ & $-.16(.37)$ \\
\hline
\end{tabular}

Alexithymic scores obtained using the Alexithymia Questionnaire for Children, Total score, F1 difficulty identifying feelings, F2 difficulty describing feelings,

F3 externally oriented thinking

$M$ migraine, $T H$ tension-type headache

${ }^{*} \mathrm{p}<.05{ }^{* *} \mathrm{p}<.01$
In relation to psychological factors, a recent epidemiologic study [16], reporting data from the WHO's World Mental Health surveys, demonstrated that a broad range of preexisting mental disorders are likely to increase the risk of subsequent onset of headache in general population samples. A temporal association between preexisting psychiatric and psychological disorders and the onset of headaches may entail different mechanism implied in emotional regulation. While the psychopathology correlated to pediatric headache has been extensively studied [30], the relation between headache and emotional regulation, in particular alexithymia, appears to be much less studied.

Findings on child and adolescent headache patients have disclosed not only a high prevalence of depression, anxiety and behavioural symptoms but even a great extent of somatic concerns, illnesses, stress, and an unhappy atmosphere in the childrearing experience [30-32]. Moreover, preliminary data suggested an association between headache symptoms and insecure attachment [33, 34], which is known to be related to alexithymia and to deficits in affective regulation [35, 36]. Affective regulation is usually acquired in the first childrearing experiences, when children learn how to name and express their affects, sharing them with their primary caregiver, who reflects their emotional expressions in playful interactions [1, 37]. This theoretical premise shapes the hypothesis that the child's alexithymia may correspond to a similar kind of emotional dysregulation in the mother [19].

The second aim of our study was to explore the mothers' emotional competence related to that of their offspring, seeking any correlation between the alexithymic scores obtained by the children/adolescents and those obtained by their mothers within our two clinical groups and within the control group. It is worth noting that no statistically significant differences emerged between the three groups of mothers (mothers of $M$, THT and control groups) as regards alexithymia (overall and considering the subscales F1, F2, F3). Statistically significant correlations were however found between the mothers' alexithymic scores and those obtained by their children in the $M$ group and in the control group. In the TTH group however the correlation between the mothers' and children's alexithymia was significant only for the F1 subscale, difficulty in identifying feelings. The results of our study therefore only partially support the hypothesis advanced by Taylor and Bagby [37] that view alexithymia as an impaired affect regulation acquired in the early years of development within the relationship with the primary caregiver: alexithymia in a child may correspond to a similar kind of emotional dysregulation in the mother. Genetics might also play a part in the etiology of alexithymia, though other social and environmental 
factors are significant in children's cognitive-affective development [12-15].

Nevertheless the lack of correlation between TTH patients, the children with the higher level of alexithymia, and their mothers points to a potentially more complex pattern of intergenerational transmission of alexithymia. A child's alexithymia may not always correspond to a mother's deficit in emotional competence or may correspond to a kind of maternal emotional dysregulation that differs from alexithymia. This is in line with a previous study conducted on a TTH sample of children and adolescent patients [19] who generally scored higher than their mothers in alexithymia. Moreover the highest alexithymic scores in children seemed to be associated with the lowest scores in their mothers. It is worth noting that even studies concerning different pathologies, such as eating disorders, have found no correspondence between alexithymia in the offspring and in their mothers [38, 39]; on the contrary children's alexithymia seemed to correspond to mothers' tendency to overexpress their feelings [38]. These studies suggest that potential deficits in the emotional competence and in affective regulation can be expressed in a different way by the mothers and by their children. The results obtained in this study on TTH patients also point to a nonlinear transmission of alexithymia from mother to child, confirming previous results in children and adolescent samples [19].

In line with this result, the mothers of the three groups ( $\mathrm{M}, \mathrm{TTH}$ and control) showed no differences in alexithymic scores. This means that the mothers of patients with headaches did not show higher levels of alexithymia compared to other mothers. Differences, if any exist, between mothers of TTH and M patients and mothers of the control group, might lie in other aspects of emotional regulation implied in mood and anxiety disorders, which have an high incidence in parents of children with headache [17, 40, 41]. Future studies exploring these aspects may be useful to tackle important stressors and risk factors for the onset of headaches in genetically predisposed children [16, 17].

Exploring any potential relationship between gender and alexithymic traits in young headache sufferers, we found no statistically significant differences between male and females in our sample's alexithymic traits. The only exception being the F3 factor, where males suffering from $\mathrm{M}$ scored higher than females in the $\mathrm{M}$ group. Although the small number of males within the samples might have limited the possibility of exploring gender differences in greater depth, these results are in line with literature [23, 42, 43]. Although gender differences were reported by studies conducted on adult samples [44, 45], in adolescent $[42,43]$ and child [23] samples differences are much less obvious than in an adult population.
Concerning the age factor, no differences emerged within the TTH and the control groups, while in the $M$ group the alexithymic score was inversely proportional to age, except for the F2. This is in line with the decay of alexithymia documented from childhood to adolescence [42]. Such an event could be partially explained by the fact that cognitive skills regulating interpersonal relations and affective regulation reach full development in adolescence [19].

The main limitations of this study need to be mentioned in order to pave the way for future research in this field. One of the weaknesses of this study is that the data are based only on self-reported emotional difficulties while, as generally known, a multi-informant evaluation may be more precise and valuable, especially in detecting emotional difficulties, which young people might not always be completely aware of [37]. Nonetheless the Alexithymia Questionnaire for Children's rewording [23], tailored specifically to children, could in part overcome the limitation due to the difficult self-reported evaluation for younger age groups. Such a self-reported instrument has proven to be useful and handy in conducting this study on two specific child headache samples, where alexithymic characteristics were still largely unexplored. Moreover using two theoretically similar and comparable measures for the child's (AQC) and the mother's (TAS-20) alexithymia served to identify a relationship between the two. Subsequent studies deserve to be carried out on the topic to examine in depth the relation between headache symptoms and emotional functioning, using clinical indices and interviewer rated instruments.

A second limitation of the study involves the limited size and the gender distribution of the three samples, where there is a prevalence of females than males. This can in part mirror the fact that there is a marked feminine prevalence of headaches in this age group. Metanalytical data [46] points to a higher risk for the onset of headache symptoms in female compared to male children and adolescents. Moreover this difference might be more marked in preadolescence and in adolescence, in particular for tension-type headache [47]. In this age group the prevalence of daily chronic headaches is even two to three fold higher in girls compared to boys [48-50]. Due to the limited size of the sample, diagnostic distinction among different kinds of $\mathrm{M}$ and TTH was taken into account only for descriptive analysis, while inferential statistics would have been less effective given the small number of subjects in the different groups. Comparing specifically chronic TTH patient's alexithymia to other TTH patients' could be an interesting objective for a future study conducted on a larger sample of patients. 
Another limitation of the study regards the missing data on paternal alexithymia. Future studies should include fathers to further explore the mechanisms involved in family emotional functioning and in the intergenerational transmission of alexithymia [38]. Close family members need to be involved in the assessment of psychological traits and emotional competencies that may constitute a risk or, on the contrary, a protective factor for the onset of the child's headache $[16,17,40,41]$.

\section{Conclusions}

Given the paucity of publications on the relation between alexithymia and primary headache in children [19] and adolescents [19, 27], our study can significantly contribute by revealing a statistically significant association between alexithymia and TTH. This is consistent with the interpretation of somatic complaints according to a paradigm of deregulated emotion, confirming the conviction that alexithymia creates a condition in which feelings, when not discriminated against, can undergo a process of reinforcement and become a symptom of disease [2-4]. Alexithymia would consequently be a risk factor for the onset of medical or psychiatric, organic or functional disorders [19, 51-53]. Moreover, it would be important to refer to factors that are not strictly organic, such as the psychological dimension, when contextualizing and managing TTH in the child and adolescent age group. These considerations converge towards a holistic and multidisciplinary approach to tackle the problem of headache.

Literature offers no data on the prevalence of alexithymic traits in children who suffer from $\mathrm{M}$ as opposed to TTH. The present study indicates that young M sufferers tend to be less alexithymic than TTH child and adolescent patients. Despite the obvious limitation of having a small sample, this study has generated some novel findings that may be a preliminary step and a starting point for further investigations in this field, oriented towards a comprehensive multidisciplinary approach in the care of children and adolescents suffering from headaches.

\footnotetext{
Abbreviations

TTH: Tension-type headache; M: Migraine; ICHD: International Classification of Headache Disorders; TAS-20: Toronto Alexithymia Scale; F1: Difficulty identifying feelings; F2: Difficulty describing feelings; F3: Externally oriented thinking.
}

\section{Competing interests}

The authors declare that they have no competing interests.

\section{Authors' contributions}

MG draft the manuscript, CS and LB helped to draft it. CS contributed to the acquisition of data while $A S$ and $L B$ to the analysis and interpretation. MG, $U B, A S, S M$ and PAB participated to the design of the study and revised the manuscript. All authors read and approved the final manuscript.

\section{Acknowledgements}

The authors warmly thank all of the children and mothers who took part in the study, along with all those who have supported us with their precious help.

\section{Author details}

'Department of Woman and Child Health, University of Padova, Padova, Italy. ${ }^{2}$ Department of Child and Adolescent Neuropsychiatry, University of Palermo, Palermo, Italy. ${ }^{3}$ Child Neuropsychiatry Unit, C. Mondino National Neurological Institute, Pavia, Italy. ${ }^{4}$ Child Neuropsychiatry Unit, Department of Brain and Behavioral Sciences, University of Pavia, Pavia, Italy. ${ }^{5}$ Department of General Psychology, University of Padova, Padova, Italy. ${ }^{6}$ Department of Philosophy, Sociology, Education, and Applied Psychology, Section of Applied Psychology, University of Padova, Padova, Italy.

Received: 22 May 2015 Accepted: 6 October 2015

Published online: 25 November 2015

\section{References}

1. Taylor GJ (1994) The alexithymia construct: conceptualization, validation, and relationship with basic dimensions of personality. New Trends Exp Clin Psychiatr 10:61-74

2. Taylor G (1994) Alexithymia: concept, measurement, and implications for treatment. Am J Psychiatry 141:725

3. Bermond B (1997) Brain and alexithymia. In: Vingerhoets A, van Bussen F, Boelhouwers J (eds) The (non) expression of emotion in health and disease. Tilburg University Press, Netherlands, pp 115-131

4. Taylor GJ, Bagby RM, Parker JDA (1997) Disorders of affect regulation: alexithymia in medical and psychiatric illness. Cambridge University Press, Cambridge

5. Howard B, Taryn J (1994) Correlates and retrospectively reported antecedents of alexithymia. Psychosom Med 56(4):353-359

6. Parker JDA, Taylor GJ, Bagby RM (1993) Alexithymia and the recognition of facial expressions of emotion. Psychother Psychosom 59:197-202

7. Jessimer M, Markham R (1997) Alexithymia: a right hemisphere dysfunction specific to recognition of certain facial expressions? Brain Cogn 34:246-258

8. Hoppe KD, Bogen JE (1976) Alexithymia in twelve commissurotomized patients. Psychother Psychosom 28:148-155

9. Parker JD, Keightley ML, Smith CT, Taylor GJ (1999) Interhemispheric transfer deficit in alexithymia: an experimental study. Psychosom Med 61(4):464-468

10. Bermond B (1995) Alexithymia, a neuropsychological method of approach. J Psychiatry 37:717-727

11. Ham BJ, Lee MS, Lee YM, Kim MK, Choi MJ, Oh KS, Jung HY, Lyoo IK, Choi IG (2005) Association between the catechol O-methyltransferase al108/158Met polymorphism and alexithymia. Neuropsychobiology 52(3):151-154

12. Heiberg A, Heiberg A (1978) A possible genetic contribution to the alexithymia trait. Psychother Psychosom 30(3-4):205-210

13. Valera EM, Berenbaum H (2001) A twin study of alexithymia. Psychother Psychosom 70(5):239-246

14. Jørgensen MM, Zachariae R, Skytthe A, Kyvik K (2007) Genetic and environmental factors in alexithymia: a population-based study of 8785 Danish twin pairs. Psychother Psychosom 76:369-375

15. Picardi A, Fagnani C, Gigantesco A, Toccaceli V, Lega I, Stazi MA (2011) Genetic influences on alexithymia and their relationship with depressive symptoms. J Psychosom Res 71:256-263

16. Bruffaerts $R$, Demyttenaere K, Kessler RC, Tachimori H, Bunting B, Hu C, Florescu S, Haro JM, Lim CC, Kovess-Masfety V, Levinson D, Medina Mora ME, Piazza M, Piotrowski P, Posada-Villa J, Salih Khalaf M, ten Have M, Xavier M, Scott KM (2015) The associations between preexisting mental disorders and subsequent onset of chronic headaches: a worldwide epidemiologic perspective. J Pain 16(1):42-52

17. Seshia SS, Phillips DF, von Baeyer CL (2008) Childhood chronic daily headache: a biopsychosocial perspective. Dev Med Child Neurol 50(7):541-545

18. Kröner-Herwig B (2013) Pediatric headache: associated psychosocial factors and psychological treatment. Curr Pain Headache Rep 17(6):338

19. Gatta M, Canetta E, Zordan M, Spoto A, Ferruzza E, Manco I, Addis A, Dal Zotto L, Toldo I, Sartori S, Battistella PA (2011) Alexithymia in juvenile primary headache sufferers: a pilot study. J Headache Pain 12(1):71-80

20. Wise N, Mann S, Jani N (1994) Illness beliefs and alexithymia in headache patients. Headache 34(6):362-365 
21. Yücel B, Kora K, Ozyalçín S, Alçalar N, Ozdemir O, Yücel A (2002) Depression, automatic thoughts, alexithymia, and assertiveness in patients with tensiontype headache. Headache 42(3):194-199

22. Headache Classification Committee of the International Headache Society (2013) The International Classification of Headache Disorders, 3rd edition (beta version). Cephalalgia 33(9):629-808

23. Rieffe C, Oosterveld P, Terwogt MM (2006) An alexithymia questionnaire for children: Factorial and concurrent validation results. Pers Indiv Differ 40:123-133

24. Bagby RM, Parker JD, Taylor GJ (1994) The twenty-item Toronto Alexithymia Scale-I. Item selection and cross-validation of the factor structure. J Psychosom Res 38:23-32

25. Bressi C, Taylor G, Parker J, Bressi S, Brambilla V, Aguglia E, Allegranti I, Bongiorno A, Giberti F, Bucca M, Todarello O, Callegari C, Vender S, Gala C, Invernizzi G (1996) Validation of the factor structure of the 20-item Toronto Alexithymia Scale: an Italian multicenter study. Psychosom Res 41(6):551-559

26. Pini M, De Filippis S, Farinelli I, Martelletti P (2008) Alexithymic features and emotional distress in patients with chronic tension-type headache (CTTH) and medication-overuse headache (MOH). Clin Ter 159(6):397-403

27. Balaban H, Semiz M, Şentürk IA, Kavakçı Ö, Cınar Z, Dikici A, Topaktaş S (2012) Migraine prevalence, alexithymia, and post-traumatic stress disorder among medical students in Turkey. J Headache Pain 13(6):459-467

28. Neyal-Muftuoglu M, Herken H, Demirci H, Virit O, Neyal A (2004) Alexithymic features in migraine patients. Eur Arch Psychiatry Clin Neurosci 254(3):182-186

29. Vieira RV, Vieira DC, Gomes WB, Gauer G (2013) Alexithymia and its impact on quality of life in a group of Brazilian women with migraine without aura. J Headache Pain 14(1):18

30. Balottin U, Fusar Poli P, Termine C, Molteni S, Galli F (2013) Psychopathological symptoms in child and adolescent migraine and tension-type headache: a meta-analysis. Cephalalgia 33(2):112-122

31. Kernick D, Campbell J (2009) Measuring the impact of headache in children: a critical review of the literature. Cephalalgia 29(1):3-16

32. Liakopoulou-Kairis M, Alifieraki T, Protagora D, Korpa T, Kondyli K, Dimosthenous E, Christopoulos G, Kovanis T (2002) Recurrent abdominal pain and headache. Psychopathology, life events and family functioning. Eur Child Adolesc Psychiatry 11(3):115-122

33. Berry JK, Drummond PD (2014) Does attachment anxiety increase vulnerability to headache? J Psychosom Res 76(2):113-120

34. Esposito M, Parisi L, Gallai B, Marotta R, Di Dona A, Lavano SM, Roccella M, Carotenuto M (2013) Attachment styles in children affected by migraine without aura. Neuropsychiatr Dis Treat 9:1513-1519

35. Montebarocci O, Codispoti M, Baldaro B, Rossi R (2004) Adult attachment style and alexithymia. Pers Individ Dif 36(3):499-507

36. Pedrosa Gil F, Scheidt CE, Hoeger D, Nickel M (2008) Relationship between attachment style, parental bonding and alexithymia in adults with somatoform disorders. Int J Psychiatry Med 38(4):437-451

37. Taylor GJ, Bagby RM (2004) New trends in alexithymia research. Psychother Psychosom 73:68-77

38. Balottin L, Nacinovich R, Bomba M, Mannarini S (2014) Alexithymia in parents and adolescent anorexic daughters: comparing the responses to TSIA and TAS-20 scales. Neuropsychiatr Dis Treat 10:1941-1951

39. Pace CS, Cavanna D, Guiducci V, Bizzi F (2015) When parenting fails: alexithymia andattachment states of mind in mothers of female patients with eating disorders. Front Psychol 6:1145

40. Feldman JM, Ortega AN, Koinis-Mitchell D, Kuo AA, Canino G (2010) Child and family psychiatric and psychological factors associated with child physical health problems: results from the Boricua youth study. J Nerv Ment Dis 198(4):272-279

41. Marmorstein NR, lacono WG, Markey CN (2009) Parental psychopathology and migraine headaches among adolescent girls. Cephalalgia 29(1):38-47

42. Karukivi M, Hautala L, Kaleva O, Haapasalo-Pesu KM, Liuksila PR, Joukamaa M, Saarijärvi S (2010) Alexithymia is associated with anxiety among adolescents. J Affect Disord 125(1-3):383-387

43. Sakkinen P, Kaltiala-Heino R, Ranta K, Haataja R, Joukamaa M (2007) Psychometric properties of the 20-Item Toronto Alexithymia Scale and prevalence of alexithymia in a Finnish adolescent population. Psychosomatics 48:154-161

44. Mattila AK, Salminen JK, Nummi T, Joukamaa M (2006) Age is strongly associated with alexithymia in the general population. J Psychosom Res 61(5):629-635
45. Salminen JK, Saarijärvi S, Aärelä E, Toikka T, Kauhanen J (1999) Prevalence of alexithymia and its association with sociodemographic variables in the general population of Finland. J Psychosom Res 46(1):75-82

46. Abu-Arafeh I, Razak S, Sivaraman B, Graham C (2010) Prevalence of headache and migraine in children and adolescents: a systematic review of population-based studies. Dev Med Child Neurol 52(12):1088-1097

47. Blaauw BA, Dyb G, Hagen K, Holmen TL, Linde M, Wentzel-Larsen T, Zwart JA (2014) Anxiety, depression and behavioral problems among adolescents with recurrentheadache: the Young-HUNT study. J Headache Pain 15:38

48. Arruda MA, Guidetti V, Galli F, Albuquerque RC, Bigal ME (2010) Frequent headaches in the preadolescent pediatric population: a population-based study. Neurology 74(11):903-908

49. Seshia SS, Wang SJ, Abu-Arafeh I, Hershey AD, Guidetti V, Winner P, WöberBingöl C (2010) Chronic daily headache in children and adolescents: a multi-faceted syndrome. Can J Neurol Sci 37(6):769-778

50. Wang SJ, Fuh JL, Lu SR, Juang KD (2006) Chronic daily headache in adolescents: Prevalence, impact and medication overuse. Neurology 66:193-197

51. Ciarrochi J, Heaven PC, Supavadeeprasit S (2008) The link between emotion identification skills and socio-emotional functioning in early adolescence: a 1- year longitudinal study. J Adolesce 31:565-582

52. Honkalampi K, Tolmunen T, Hintikka J, Rissanen ML, Kylma J, Laukkanen E (2009) The prevalence of alexithymia and its relationship with Youth SelfReport problem scales among Finnish adolescents. Compr Psychiatry 50(3):263-268

53. Jellesma FC, Rieffe C, Terwogt MM, Westenberg M (2009) Do I feel sadness, fear or both? Comparing self-reported alexithymia and emotional taskperformance in children with many or few somatic complaints. Psychol Health 24(8):881-893

\section{Submit your manuscript to a SpringerOpen ${ }^{\odot}$ journal and benefit from:}

- Convenient online submission

- Rigorous peer review

- Immediate publication on acceptance

- Open access: articles freely available online

- High visibility within the field

- Retaining the copyright to your article

Submit your next manuscript at $>$ springeropen.com 